\title{
Design and Exploration of Saturation Diving Simulation Training System
}

\author{
Zhitao Wang, Fushan Li, Zhiguang Wang, Yanhua Xue, and Yi Yao
}

\begin{abstract}
Saturation diving simulation system is a special device used in laboratory training or training institution, its main structure is similar with saturation diving equipment, taking into account the laboratory condition, using the design of tour water tank can be pressurized to replace the simulated sea. This paper is to solve the laboratory conditions to meet the actual needs of saturation diving training teaching and training issues. In the simulated saturation diving training content function, training objects, training system is responsible for the scientific review based on the empirical data of the actual operation method of saturation diving through the investigation and analysis, the main structure composition, saturation diving performance parameters of the simulation training system and training process focuses on the issues of design scheme was adopted.
\end{abstract}

Index Terms-Composition function saturation diving training.

\section{INTRODUCTION}

Saturation diving that means divers make the inert gas of the tissue in the body reach fully saturated state under certain pressure in virtue of saturation diving equipment system, which can dive for long time and deep depth. Among them, the saturation diving equipment system is the critical support equipment [1]. Saturation diving simulation system generally refers to saturation diving training equipment used in laboratory or training institutions. It is similar to real equipment and also has the characteristics of saturation diving training in the laboratory (land). At present, the domestic saturation diving training system is still in the blank. Therefore, that building up the saturation diving simulation training system which is in accord with the actual situation of saturation diving training on land should be solved immediately, which is used to train high quality talent of saturation diving.

\section{FUNCTION}

Saturation diving simulation training system is installed in the saturation diving classroom of training institutions, which can use to teach, learn, train and research. Its main function

Manuscript received December 26, 2016; revised January 26, 2017. This work was supported in part by the U.S. Department of Commerce under Grant BS123456 (sponsor and financial support acknowledgment goes here). Paper titles should be written in uppercase and lowercase letters, not all uppercase. Avoid writing long formulas with subscripts in the title; short formulas that identify the elements are fine (e.g., "Nd-Fe-B"). Do not write "(Invited)" in the title. Full names of authors are preferred in the author field, but are not required. Put a space between authors' initials.

Zhitao Wang is with the PLA Navy Submarine Academy Diving Training Center Engineer, China (e-mail: wangzhitao134@126).

Fushan $\mathrm{Li}$ is the Naval Command in charge of diving professional senior engineer, Navy Level Diver, China (e-mail:13358667278@126.com).

Zhiguang Wang is with the Naval Submarine Academy Diving Instructor, Associate Professor, Navy Level Diver, China (e-mail: qdqtxywzg@163.com). includes:

1) For individual (jobs) skills training and testing about saturation diving;

2) For comprehensive training and testing about saturation diving,

3) For emergency disposal training and testing about saturation diving;

4) For the simulation diving training of the diver,

5) For oxygen sensitive test of divers;

6) For special diving disease treatment and research [2];

7) For scientific research and test task in related fields [3].

\section{TRAINING OBJECTS}

In order to meet the practical needs of saturated diving training objectives set and training objectives are as follows [3].

8) The supervision for saturation diving

9) The lifeguard for saturation diving

10)The doctor for saturation diving

11)The personnel of gas distribution for saturation diving

12)Saturation divers

13)Bounce divers

14)Other relevant control personnel

\section{TRAining CONTENTS}

Saturation (Bounce) Diving Training

15)Skills training for diving supervision, diving doctor and the personnel of gas distribution [4];

16)Control training for life support system of diving cabin or diving-bell used for keeping steady pressure or compression or decompression or oxygen supplement;

17)The environment control and operation and maintenance of life support equipment;

18)Divers training under the saturated condition;

19)Bounce diving training;

20)Operation and training test for saturation diving;

21)Simulation exercise of failure mode in emergency (emergency disposal).

22)Simulation Diving Training for Divers

23)Oxygen Sensitive Test for Divers [5]

\section{MAIN TECHNICAL INDICATORS}

\section{A. Capacities}

1) The capacity of No. 1 living accommodation is 
greater than 4 people (saturation diving), and oxygen sensitive test 10 people;

2) The capacity of No. 2 living accommodation is greater than 4 people (saturation diving), and oxygen sensitive test 10 people;

3) The capacity of transitive cabin is no less than 3 people;

4) The capacity of diving-bell is no less than 3 people;

5) Excursion diving cabin can accommodate two people at one time at most.

\section{B. The Maximum Working Pressure}

1) Living accommodation, transitive cabin is greater than 2.0 $\mathrm{MPa}$;

2) Excursion diving cabin is greater than $2.0 \mathrm{MPa}$;

3) Diving-bell is greater than 0.3 MPa.

\section{The Environmental Temperature and Humidity}

1) Living accommodation, transitive cabin: temperature (setting range/control deviation) the medium is nitrogen and oxygen: $25^{\circ} \mathrm{C} \sim 28^{\circ} \mathrm{C} / \pm 1{ }^{\circ} \mathrm{C}$; the medium is helium and oxygen: $30{ }^{\circ} \mathrm{C} \sim 36^{\circ} \mathrm{C} / \pm 1{ }^{\circ} \mathrm{C}$.

2) Humidity: $55 \% \sim 75 \%$.

3) Excursion diving cabin (temperature range/control deviation): $15^{\circ} \mathrm{C} \sim 26{ }^{\circ} \mathrm{C} / \pm 1^{\circ} \mathrm{C}$.

4) $\mathrm{CO} 2$ partial pressure $<0.5 \mathrm{kpa}$.

\section{THE STRUCTURE AND COMPOSITION}

This training system includes seven subsystems as following pressure cabin assembly and its supporting system, diving-bell assembly and its supporting system, crane system, comprehensive monitoring system, emergency training and testing system, power supply and distribution system, equipment cooling water system.

\section{A. Pressure Cabin Assembly and its Supporting System}

Fig. 1 pressure cabin assembly diagram)

1) The pressure cabin (No. 1 living accommodation, No. 2 living accommodation, transitive cabin, excursion diving cabin) ontology (including hull structure, medical lock, faceplate);

2) The pressure cabin air system (comprehensive console of pressure cabin, air supply pipeline of pressure cabin);

3) The environmental control system (main engine of environmental control, control unit of environmental control, machine in cabin of environmental control, $\mathrm{CO} 2$ removal device);

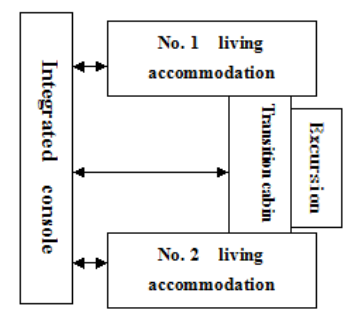

Fig. 1. Pressure cabin assembly diagram.

4) Health systems;

5) Communication system, monitoring system, lighting system, sound and light alarm system, entertainment system;

6) The monitoring systems for divers' vital-sign.

\section{A. Living Accommodation}

Both living accommodations are horizontal container can bear internal pressure, at both ends are oval head, and in the middle is the column shell. There is a gateway to the outside at the end of cabin, which is used circular pressure gate bear one-way pressure. At the other end there is an entrance interlinked with transitive cabin, which is used two circular pressure doors bear one-way pressure. There is a non-pressure partition in the living accommodation, which is equipped with square door. Therefore the cabin is divided into two parts, one for living accommodation of divers, another for the bathroom.

Medical lock is on the cabin body, where has a pressure self-locked device on the cover outside cabin. When the canister with pressure, it can't open the out cover by self-lock, which is used to ensure safety. Covered with insulation layer on the appearance of cabin body, which is for heat preservation. On the top of the cabin there is LED cold light source to light for inner cabin. Observation window is equipped at the two sides of the cabin body, which is used to observe the situation of inner cabin by outside cabin crew. Projection window is laid on the cabin body, which can play video image on the screen by the projector set up outside cabin. Divers can watch TV and video in the cabin with head-mounted earphone. It also has the system for diver physiological indexes testing and signal transmission by cable and wireless.

\section{B. Transitive Cabin}

Transitive cabin is a transition space where living accommodation goes to excursion diving cabin or passageway cabin (when the cabin with pressure), each side of cabin body is equipped with a channel linked into the living accommodation, and also has another exit to the outside cabin, where for divers entrance and exit. During operation time (When the living accommodation with pressure), individual divers in cabin need to go out of the cabin in advance for some reasons, then they can be transferred to the transitive cabin for decompression; When divers out of cabin need to come in, they also can be transferred to the transitive cabin for compression, then come into living accommodation after the pressure is balance to it. Channels are equipped with a pressured cover. The channel at the bottom of transitive cabin is connected with excursion diving cabin, systems and equipments related to divers diving are laid inside of transitive cabin. On the large depth saturation diving, divers dive to excursion diving cabin directly after dressing in the transitive cabin, where transitive cabin is simulated to diving-bell.

Transitive cabin is a monomer pressured container imitation diving-bell, excursion diving cabin is a monomer pressured cylindrical container; the two cabins connected together by welding. The upper part is transitive cabin, what length is 2.3 meters; and the lower part is for excursion diving cabin, what length is 3.7 meters. Transitive cabin from the top down 2.3 meters is 
installed separation net, which is used to separate transitive cabin and excursion diving cabin, also used to stand and exercise by crew and to hold diving fittings. A vertical hinged door can open and close is set on separation net. Diving ladder is set on the corresponding position of excursion diving cabin, as the channel for divers dive into the water. There are 3 diving fittings in the cabin. There is an observation window on the column hull of transitive cabin what diameter is $200 \mathrm{~mm}$; there are four observation windows on excursion diving cabin what diameter is also $200 \mathrm{~mm}$. A medical lock that the inner diameter is $450 \mathrm{~mm}$ and length is $750 \mathrm{~mm}$ is set on the transitive cabin, which is used to deliver diving fittings, operation equipments and tools. There is a manual hoist crane on the top of transition cabin, which is used to lift weights, or assist divers to return transitive cabin.

(Table I Pressure Cabin Assembly and its Supporting System).

The related equipment to diver saturation diving laid in transitive cabin, mainly includes divers' umbilical, helmet-type camera and diving toolkit etc. Divers umbilical is connected with the related system outside cabin by connector assembly on cabin, which can provide the channels of gas, communication, lighting necessary to divers; the helmet-type camera may be placed on a helmet, can also be hold type camera combined with the handle; the diving kit can provide frequently-used diving tool for divers. Excursion diving cabin is installed underwater cameras not less than 4 and a number of lights, to provide the necessary monitoring and inspection clear images of various perspectives, and to record video playback provide the basis for training and evaluation. The independent pressure system is installed inside transitional cabin, mainly used to simulate the process of adjust pressure through diving-bell on saturation diving.

TABLE I: PRESSURE CABIN ASSEMBLY AND ITS SUPPORTING SYSTEM

\begin{tabular}{|c|c|c|c|}
\hline $\begin{array}{c}\text { Serial } \\
\text { number }\end{array}$ & $\begin{array}{c}\text { Structure } \\
\text { name }\end{array}$ & major function & Remarks \\
\hline 1. & Residence & $\begin{array}{l}\text { Cabin for divers to rest, } \\
\text { stay and live during } \\
\text { saturation diving }\end{array}$ & $\begin{array}{l}2 \text { sets } \\
\text { Mutual } \\
\text { standby }\end{array}$ \\
\hline 2. & $\begin{array}{l}\text { Transfer } \\
\text { chamber }\end{array}$ & $\begin{array}{l}\text { It is the transition space of } \\
\text { the living room leading to } \\
\text { the patrol cabin or entry } \\
\text { and exit cabin. }\end{array}$ & 1 set \\
\hline 3. & $\begin{array}{c}\text { Patrol } \\
\text { submarine }\end{array}$ & Simulated sea & 1 set \\
\hline 4. & $\begin{array}{l}\text { Pressure } \\
\text { Cabin Air } \\
\text { System }\end{array}$ & $\begin{array}{l}\text { Mainly used for ballast } \\
\text { system, and with pressure, } \\
\text { pressure, gas analysis, } \\
\text { oxygen supply and gas } \\
\text { supply apparatus. }\end{array}$ & 1 set \\
\hline 5. & $\begin{array}{l}\text { Environment } \\
\text { al Control } \\
\text { System }\end{array}$ & $\begin{array}{l}\text { The system is used for the } \\
\text { automatic adjustment of } \\
\text { the environmental } \\
\text { temperature in the cabin, } \\
\text { the dehumidification and } \\
\text { the clearance of } \mathrm{CO}_{2} \text { in the } \\
\text { cabin. }\end{array}$ & $\begin{array}{l}2 \text { sets } \\
\text { Mutual } \\
\text { standby }\end{array}$ \\
\hline 6. & $\begin{array}{l}\text { Integrated } \\
\text { monitoring } \\
\text { system }\end{array}$ & $\begin{array}{l}\text { It mainly completes the } \\
\text { functions of signal } \\
\text { detection, fault alarm and } \\
\text { so on, such as the living }\end{array}$ & 1 set \\
\hline
\end{tabular}

\begin{tabular}{|c|l|l|l|}
\hline & & $\begin{array}{l}\text { room, the transition cabin, } \\
\text { the control system, the } \\
\text { health system and so on. }\end{array}$ & \\
\hline 7. & $\begin{array}{c}\text { Diver vital } \\
\text { signs } \\
\text { monitoring } \\
\text { system }\end{array}$ & $\begin{array}{l}\text { The main responsibility for } \\
\text { divers breathing, heartbeat, } \\
\text { body temperature, blood } \\
\text { pressure and other vital } \\
\text { signs detection }\end{array}$ & 1 set \\
\hline 8. & $\begin{array}{l}\text { Saturation } \\
\text { diving } \\
\text { electronic } \\
\text { information } \\
\text { service system }\end{array}$ & $\begin{array}{l}\text { It is mainly used for data } \\
\text { processing, process } \\
\text { monitoring, data acquisition } \\
\text { and recording, and so on. }\end{array}$ & 1 set \\
\hline
\end{tabular}

\section{Pressure Cabin Air System}

Pressure cabin air system includes compression, decompression, pressure measuring, gas analysis, oxygen supply and air supply by respirator and so on; the operation of this system mainly concentrates in the compression console.

\section{1) Compression and decompression in pressure cabin}

That compression and decompression to living accommodation, transitive cabin and the top channel in transitive cabin may be carried by manual way. The maximum rate of compression is $0.18 \mathrm{MPa} / \mathrm{min}$ (cabin pressure is lower than 2 bar); the maximum rate of decompression is $0.08 \mathrm{MPa} / \mathrm{min}$ [7]. The independent pipeline for compression and decompression is laid in the living accommodation, transitive cabin and diving-bell. That compression and decompression to living accommodation, transitive cabin can operate through integrated console. Keep steady pressure by manual operation. Pressurized pipe connects with silencer on the outlet inner cabin. The control valve and meter of system is mainly concentrated in the comprehensive console of pressure cabin.

\section{2) Gas analysis in pressO2ure cabin}

To test gas composition of the living accommodation, where is equipped with $\mathrm{CO}_{2}$ and $\mathrm{O}_{2}$ analyzer. The total system mainly includes $\mathrm{CO}_{2}$ analyzer, $\mathrm{O}_{2}$ analyzer, filter, exsiccate, flow meter, standard analysis gas cylinder, etc. All equipments are laid on the comprehensive console of pressure cabin control room [8].

\section{3) Oxygen supply to pressure cabin}

That supply oxygen to pressure cabin, is to assure the oxygen partial pressure in cabin to keep set range. It is mainly composed of the decompression valve, stop valve, and oxygen supply pipe, etc. Various operating valves are mainly laid on the comprehensive console of pressure cabin control room. Oxygen in oxygen sensitivity test is supplied by oxygen pipeline in the gas storage system, while oxygen in saturation diving by special oxygen cylinder [9].

\section{4) Air supply by respirator in pressure cabin}

It is mainly consist of valve, pressure gauge and piping. Oxygen and helium gas is supplied to divers in living accommodation and transitive cabin by the comprehensive console of pressure cabin according to 
the requirements of procedure.

Both respirator supply valve and exhaust valve are laid in pressure cabin; each live accommodation has 10 sets and 3 sets in transitive cabin. Supply valve and exhaust valve are connected with the respirator supply and exhaust pipe respectively. Compression valve is laid on the gas supply pipe, which can adjust gas supply pressure by manual; back pressure valve is laid on the gas exhaust pipe, it will automatically cut off the gas path when the control chamber pressure is lower than the back pressure setting value.

\section{5) Piezometric pipeline}

The independent piezometric pipeline is laid in living accommodation and transitive cabin, which is used for real-time measurement of cabin pressure. Piezometric pipeline is mainly composed of valve, pipe, precision pressure gauge, etc. Each cabin has two precision pressure gauges which span set on $0-100 \mathrm{~m}$ and $0-400$. The precision pressure gauge is laid on the console of each cabin.

\section{Environmental Control System}

The system is used for environment temperature automatic adjustment, dehumidification and $\mathrm{CO}_{2}$ removal of living accommodation. Equipped with two extravehicular machines, bridge pipeline is installed on the system, as spare when necessary.

This system is adopt to internal-circulation environment control equipment, two extravehicular machines are equipped outside cabin, two board machines in each cabin, extravehicular machine can provide refrigerant water and heat medium water to board machine, board machine can adjust the temperature of environment gas and remove $\mathrm{CO}_{2}$. A $\mathrm{CO}_{2}$ cleaner is equipped in each living accommodation (transitive cabin also has one), which is used to remove $\mathrm{CO}_{2}$ in cabin when board machine doesn't work properly. Remote control panel is laid on the comprehensive console of cabin control room.

Main technical parameters are as follows:

Temperature control range is $24{ }^{\circ} \mathrm{C} \sim 35^{\circ} \mathrm{C} / \pm 1^{\circ} \mathrm{C}$.

On normal humidification conditions in cabin, humidity control range of $50 \%-70 \% \pm 10 \%$; The $\mathrm{CO}_{2}$ partial pressure < $0.5 \mathrm{KPa}[10]$.

The cabin noise caused by the work of environmental control system is not greater than $60 \mathrm{db}$.

\section{E. Health System}

This system is used to supply hot and cold washing water, eliminate the sewage and bilge water. The main equipment includes water supply pressurized device, sanitary ware, and dirt storage containers, etc. The system adopts the way of pressurized water supply.

1) Sanitary ware is equipped in living accommodation, including a shower, a toilet and a lavatory. There is a dirt storage container and related pipeline system on bilge.

2) Communication system

This system is used for internal communication, which includes helium oxygen voice calls, sound powered telephone and digital loud speaking integrated communication system.

Helium oxygen voice calls is the main communications equipment on diving, which is used to communicate between personnel in living accommodation, transitive cabin and outside cabin.
Sound powered telephone is used as an alternate means of communication, laid on outside cabin, which is used to communicate between personnel in living accommodation, transitive cabin and outside cabin.

3) Sound and light alarm

Sound and light alarm system is mainly used for the two-way acousto-optic signal alarm between living accommodation, transitive cabin and outside cabin, so that when any one is in an emergency, the personnel can alarm with sound and light signal to the other.

\section{F. Monitoring System}

This system adopts the structure of distributed computer monitoring system, which is mainly used for signal detection, fault alarm to the living accommodation, transitive cabin, environmental control system, health systems and so on.

\section{G. Diving-Bell Assembly and its Supporting System}

In order to bounce diving training, we studied the design of the diving bell assembly and its supporting system. As an independent unit of saturation diving system, the diving-bell assembly and its supporting system is decorated beside the diving pool, which is not docked with the saturation diving cabin group (Fig. 2 Schematic diagram of diving bell assembly).

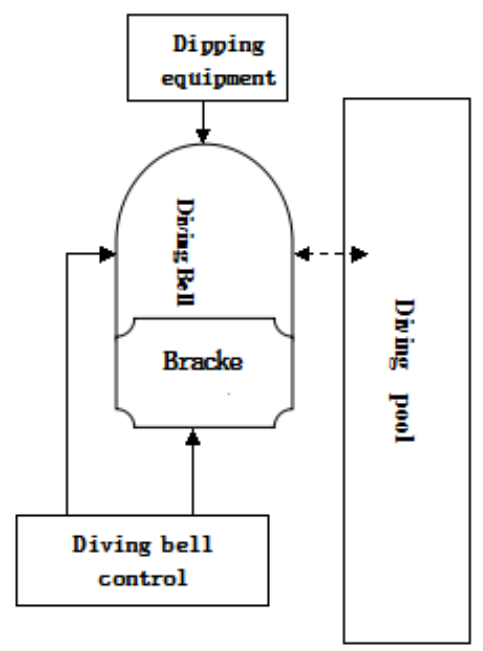

Fig. 2. Schematic diagram of diving bell assembly.

Diving-bell ontology (structure of bell, observation window, faceplate, interior fitting-out, buoyancy material laying, protection frame). The thickness of the bell is allowed to adjust after checking; diving-bell is used to transport divers to the pool, the equipment what diving needed is deployed in diving-bell, including diving-bell ontology (with frame and observation window, etc.), bell umbilical, divers umbilical, trachea, valves and accessories, communications, video, lighting facility, etc. Diving-bell should be designed simplify, based on the feature of diving training under the condition of laboratory( Table II Diving-Bell Assembly and its Supporting System).

Diving-bell ontology is composed of two hemisphere hull seal head what diameter is $1.85 \mathrm{~m}$ and one cylindrical shell what length is $0.35 \mathrm{~m}$ between them. There is a passageway what diameter is $700 \mathrm{~mm}$ at the side and 
bottom of diving-bell, respectively for divers come in and go out the bell from surface and underwater. Two layer of hatch cover inside and outside is set at the passageway, a camera observation window what diameter is $150 \mathrm{~mm}$ is set at the top of the diving-bell.

TABLE II: DIVING-BELL ASSEMBLY AND ITS SUPPORTING SYSTEM

\begin{tabular}{|c|c|c|c|}
\hline $\begin{array}{c}\text { Serial } \\
\text { number }\end{array}$ & $\begin{array}{c}\text { Structure } \\
\text { name }\end{array}$ & $\begin{array}{l}\text { Major } \\
\text { function }\end{array}$ & Remarks \\
\hline 1. & Diving Bell & $\begin{array}{l}\text { Diving Bell is mainly used to } \\
\text { transport divers into and out } \\
\text { of the water, to ensure the } \\
\text { completion of underwater } \\
\text { patrol and underwater } \\
\text { decompression training. }\end{array}$ & $1 \mathrm{set}$ \\
\hline 2. & $\begin{array}{l}\text { Diving-bell } \\
\text { gas system }\end{array}$ & $\begin{array}{l}\text { The utility model is mainly } \\
\text { used for monitoring the } \\
\text { pressure of the diving bell, } \\
\text { the exhaust, the diver's } \\
\text { breathing gas supply and the } \\
\text { underwater depth } \\
\text { measurement of the diver and } \\
\text { the diving bell. }\end{array}$ & $1 \mathrm{set}$ \\
\hline 3. & $\begin{array}{c}\text { Diving Bell } \\
\text { environment } \\
\text { control system }\end{array}$ & Carbon dioxide removal. & $1 \mathrm{set}$ \\
\hline 4. & $\begin{array}{c}\text { Emergency } \\
\text { diving system. }\end{array}$ & $\begin{array}{l}\text { Emergency diving system. } \\
\text { Mainly used for diving bell } \\
\text { emergency buoyancy } \\
\text { training. }\end{array}$ & $1 \mathrm{set}$ \\
\hline
\end{tabular}

Three observation windows what diameter is $200 \mathrm{~mm}$ are set in the middle and lower of diving-bell. Protection frame is equipped with external bell.

(2) Diving-bell gas system (diving-bell comprehensive console, umbilical, diving-bell gas pipeline). According to training needs under laboratory conditions, it should adjust appropriately connection form between diving-bell and umbilical and shorten the diver umbilical length.

This system mainly includes the following functions:

(3) Diving-bell compression and gas exhaust;

(4) Air supply to divers and underwater depth measurement for divers and diving-bell;

Monitoring to internal pressure, external pressure and gas composition of diving-bell, all include compression, air supply, pressure measurement, gas exhaust, gas detection and so on are done on the operation panel of diving-bell comprehensive console. The diver air supply panel set up more safely air supply protection function, once surface air supply or emergency air supply fails, it can automatically switchover for air supply, and provide sound and light alarm, to ensure the safety of divers ${ }^{[11]}$. There are four umbilical piezometric tubes, among them three are connected to the diving-bell by pipe penetration piece, another one is outside bell, respectively is used to measure the diving depth of divers and the water depth where diving-bells is. There are four cylinders on the diving-bell, which capacity is $40 \mathrm{~L}$ and pressure is $15 \mathrm{MPa}$, one is oxygen, another 3 is compressed air.

\section{H. Communication System}

(Includes helium oxygen telephone, underwater acoustic communication, beacon machine, flashing light), monitored control system, lighting system, sound and light alarm system;

\section{Environmental Control System}

$\left(\mathrm{CO}_{2}\right.$ removal system, pipe system);

M. Diving-bell floating system in emergency (includes droppable ballast device, main cable release and umbilical shear device, mooring release device, diving-bell hydraulic system in emergency)

This system is mainly simulated to the related system of diving-bell on ship, which is used for diving-bell floating in emergency, including diving device, manual hydraulic pump, piping, valves and accessories. It is a safety emergency system that belongs to the diving-bell exclusively.

To facilitate teaching and training, the key components of system such as diving-bell bellows cable release and umbilical shear device, mooring relief mechanism, droppable ballast release device, manual hydraulic system etc are consistent with the real ship. Because the project is not suitable for operating in teaching and training, the operating handle in bell only satisfy the requirement and purpose of the simulation training.

\section{J. Crane System}

Crane system is used to lift diving-bell to the top of diving pool from location, and then put it into the diving pool, and recycle.

Diving-bell is a kind of manned submersible, for the safety of divers special lifting (girder crane) system is used to control moving and laying of diving-bell in this system, which need to design and test according to corresponding specifications and requirements of diving-bell hanging system. This system needs to simplify and adjust the diving-bell umbilical. The umbilical doesn't need to pan, only constraint the swing position. It doesn't need to install the umbilical power pulley, while using artificial dish. Meanwhile, that the data and signal of relevant to diving-bell crane equipment is required to display on the diving-bell comprehensive console.

\section{K. Comprehensive Monitoring System}

The subsystem is mainly used for integrated control, equipment operation parameters collection and display and save, fault protection and processing to the part of saturation diving training system or device in central, which is mainly composed of the microcomputer monitor console, health system control box, equipment cooling water system of control box, etc.

1) The microcomputer monitor console: process, display and record the single from other equipment of comprehensive monitoring system.

2) Diving-bell crane console: control the craning process of diving-bell; display and record the data and single relevant to diving-bell crane equipment; send relevant data to the microcomputer monitor console.

3) Hydraulic system start-up cabinet: control starting and stopping of hydraulic machine set; display the state of hydraulic machine set, provide protection for the hydraulic machine set; send relevant data 
signals to the hydraulic system control cabinet.

4) Hydraulic system control cabinet: control hydraulic system; process the relevant data signals of hydraulic station and sent to the microcomputer monitor console.

5) Health system control box: control the operation of health system; display the state and relevant data of health system; send relevant data to the microcomputer monitor console.

6) Equipment cooling water system control box: control equipment cooling water system operation; display the state and relevant data of equipment cooling water system, send relevant data to the microcomputer monitor console.

7) Excursion diving cabin console: operate and control water and gas supply to excursion diving cabin; pressure detection and control in cabin; send data to the microcomputer monitor console.

\section{Power Supply and Distribution System}

This system includes: power distribution cabinet, uninterruptible power supply, emergency generator, distribution box.

\section{Saturation Diving Emergency Training and Testing System}

This system is training one that independent to real equipment and exists singly, which can use for training and examination in laboratory under normal condition and emergency condition. This system can provide key operation training and examination on comprehensive console in saturation cabin and diving-bell, divers' key operation training and examination in saturation cabin and diving-bell. The system operation interface should bring into correspondence with real equipment as far as possible; the operation results would feedback in the form of computer simulation. It can judge the accuracy of operation combined with the operation standard, record, analysis and playback the operation process.

1) Diving-bell manipulation training and examination system

2) Living accommodation manipulation training and examination

3) Diving-bell crane simulation console

4) Emergency disposal training system

Saturation diving is the key technology of human directly into the deep sea space, in offshore oil development, has a great application prospect in military maritime security operations, to meet the construction of saturation diving training simulation system of the practical training needs of the environmental conditions in the laboratory, to carry out teaching and training to ensure saturation diving training institutions, training of low cost high efficiency, the design scheme has been proposed by experts praise, successfully passed the acceptance.

\section{CONCLUSION}

The construction of saturation diving training simulation system can simulate the diving bell, use water tank using tour transition cabin to simulate the sea, because the upper air cushion pressure water tank circuit is adjustable, the change of air cushion pressure means that the diving depth of tank circuit realization of the adjustable. In the laboratory, divers can dive in the sea, and the system can effectively guarantee the teaching and training of saturation diving, and improve the teaching quality.

\section{REFERENCES}

[1] J. N. Gong, "Saturation diving technology," Naval Medical Research Institute, Shanghai, China, 1996.

[2] C. C. Li, "Diving medicine and protection," 2st Endplay Navy Submarine Academy Press, pp. 54-77, February 2011.

[3] Q. H. Yu, "Diving medical," Navy Submarine Academy Press, 1st ed., ch.4, pp. 85-112, February 2009.

[4] Z. G. Wang, "Self-guided diving technology," PLA Navy Submarine Academy Press, 1st ed., ch.2-5, pp. 35-162, July 2003.

[5] Y. H. Xue, "Air diving technology," PLA Navy Submarine Academy Press, 1st ed., ch.3, pp. 55-87, June 2001.

[6] Z. G. Wang, "Diving technology," Navy Submarine Academy Press, 2st ed., ch.5, pp. 112-146, February 2000.

[7] Technical requirements for decompression sickness, GB/T 17870.

[8] X. H. Li, Diving gas [M], Qingdao Ocean Press, 2st ed., ch2, pp. 23-47, Jan. 2007.

[9] D. G. Yang, "The application of saturation diving technique in submarine rescue in the Navy salvage," Diving Salvage offshore Summit, July 2007.

[10] United States Navy diving manual, 2rd ed, Naval command marine assurance department, pp. 23-87, 2005.

[11] Diver gas supply, GB 18985.

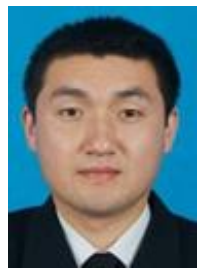

Zhitao Wang was born in September 1984 Qingdao. He is master graduate student, Naval Submarine Institute diving training center engineers, a total of more than 20 times the implementation of diving operations, organized to guide the sea diving training more than 1,000 people without accidents, in the domestic academic journals (conference ) Published papers 15 articles.

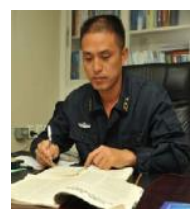

Fushan Li was born in Henan, in September 1964 $\mathrm{He}$ is a undergraduate degree, senior engineer of the Navy Command, in charge of naval diving professional construction, Navy level diver, the maximum dive depth of 91 meters. During the tenure of the implementation of the task more than 70 times, the organization and command of the sea depth of diving operations more than 50 times are safe and no accident.

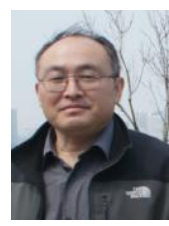

Zhiguang Wang was born in Shandong, in December 1963, He is now naval submarine college diving teaching director, an associate professor. Is a naval level divers, long engaged in diving professional direction of the teaching and training, the preparation of teaching materials 11 , published more than 30 papers, organization and command more than 5,000 people diving training safety without incident. During his tenure, he has won 23 courses such as military college quality course award, military science and technology progress award, naval excellent teaching material award and naval excellent teaching achievement prize

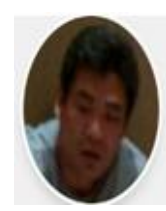

Yanhua Xue was born in Shandong, in May 1974 $\mathrm{He}$ is now naval naval submarine college diving teaching and research associate professor. Is the Navy three divers, engaged in diving professional and technical teaching and research for 20 years, the preparation of teaching materials 7 , published more than 19 papers, won the military science and technology progress award, excellent teaching material award, the Navy outstanding teaching achievement award 11.

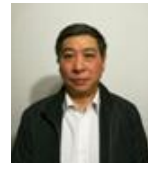

Yi Yao was born in May 1962 in Hunan. He is a master tutor, a professor of the PLA Naval Submarine Institute. Navy level divers, has long been engaged in teaching and research work, published 15 monographs, published 35 papers. Won the military science and technology progress award and the Navy outstanding teaching achievement award more than 20 items. 